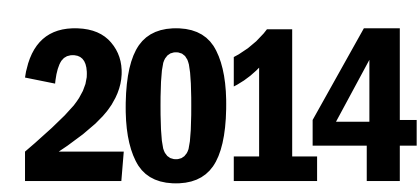

volume 11 | issue 1

an open access journal for architectural research

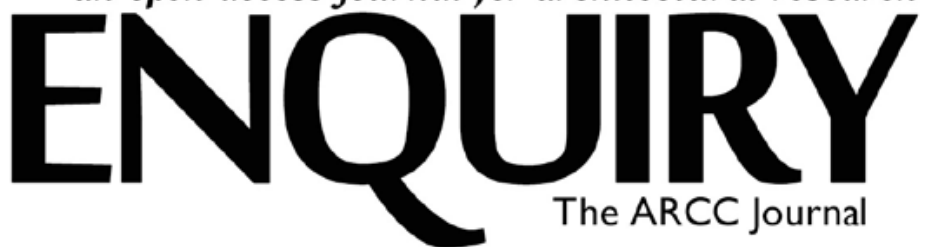

\title{
ENVIRONMENTAL DISCOURSES AND RHETORIC IN THE CONCEPTUAL SPACE OF ARCHITECTURAL EDUCATION
}

Traci Rose Rider

\begin{abstract}
This paper aims to investigate the current state and potential opportunity of strategic environmental discourses and rhetoric in architectural education. Because there is limited research completed on this specific focus, a grounded theory approach was used. In-depth interviews were held with twelve purposefully selected participants, each of whom are widely perceived as leaders in incorporating sustainability topics into architectural education. Through a cyclical coding process, larger themes about integrating environmental topics in formal architectural education emerged, with the importance of discourse and rhetoric as one of the primary sub-themes. Different discourses, emphasis on specific terminology, and the implications of each in the conceptual space of architectural educational are explored in the context of both program- and university-level structures. Breaking down the current environmental discourses in these specific contexts offers insight into opportunities to streamline the inclusion of sustainability themes in architectural education. This study concludes with possible avenues for further research regarding environmental discourse and rhetoric in architectural education, and suggestions for application in programs.
\end{abstract}

\section{Permissions and copyright}

Authors retain copyright and grant the journal right of first publication with the work simultaneously licensed under a Creative Commons Attribution License that allows others to share the work with an acknowledgement of the work's authorship and initial publication in this journal (Attribution-ShareAlike).

\section{Creative Commons Attribution 3.0 Unported (CC BY 3.0)}

You are free to: Share - copy and redistribute the material in any medium or format. Adapt — remix, transform, and build upon the material for any purpose, even commercially. The licensor cannot revoke these freedoms as long as you follow the license terms.

Under the following terms: Attribution - You must give appropriate credit, provide a link to the license, and indicate if changes were made. You may do so in any reasonable manner, but not in any way that suggests the licensor endorses you or your use.

No additional restrictions - You may not apply legal terms or technological measures that legally restrict others from doing anything the license permits.

\section{How to cite:}

Rider, Traci R. 2014. "Environmental Discourses and Rhetoric in the Conceptual Space of Architectural Education." Enquiry 11 (1): 1-7.

\section{INTRODUCTION}

Architectural education has historically emphasized the importance of communication, both graphically and verbally. In order to be successful in design and construction, it is necessary to effectively share creative visions so that the public can understand and appreciate the design's value. However, rarely is there an in-depth look at how verbal communication, discourse, terminology, and rhetoric impact design education. Previous literature indicates that there is a need to investigate the language used to talk about sustainable architecture. ${ }^{1}$ Specifically, this article explores different environmental discourses and rhetoric within the realm of architectural education, using in-depth interviews with a sample of architectural faculty members in accredited architecture programs around the United States.

\section{RHETORIC}

To begin to unpack the complexities of design rhetoric and how it influences architectural education, two primary uses of the term must be reviewed. In both cases, the term rhetoric indicates persuasive expressions, usually when speaking or writing, that encourage the audience to sway or move in some targeted direction or to identify with a specific cause. The two uses of the term are also uniformly concerned with effective communication, both deliberate and unintentional.

The difference between the two uses of the term rhetoric comes with additional nuances of the word. The first and most historically accurate use of the term is focused on being persuasive, but emphasizes a connectedness to everyday life and larger themes. This allows the audience to more easily internalize and relate to the concerns of the author through reflection and self-identification. The second use of the term rhetoric also focuses on the intent to be persuasive, but this more popular use often employs empty phrases, notions, and words, and is often associated with politicians and marketing. This instance is seen when people proclaim one position but act differently, or without consistency between words and actions. 


\section{DISCOURSE}

Architects and designers are familiar with several different conversational styles, or discourses, that have developed over time. These discourses focus on specific audiences or sub-disciplines, such as professional, technological, social, representational, and so on. ${ }^{2}$ For the purpose of this exploration, discourses are divided into three areas of interest: (1) between designer and client; (2) between architect and contractor; and (3) in education, where we will primarily focus. Understanding the structures of verbal interactions in these relationships is fundamental to understanding how environmental discourse and rhetoric may be strategically used in architectural education.

Different pairs of individuals or groups, or relationships between these individuals and groups, modify their discourses based on inherent limitations and conceptualizations of their interactions. ${ }^{3}$ The first coupling of interest here, between designer and client, often communicates with a slightly modified vocabulary, understanding that a client may not be familiar with specific terms or theories the designer might use in their process. The second coupling, between architect and contractor, is often more technical than conversations among peer designers, with clients, or in education. Contractors typically have little interest in the theory or reasoning behind a set of construction documents, and the discourse reflects that relationship. The third coupling is more complex, living within the conceptual space of education, and approaches conversations as though the participants are literally speaking the same language, using references, terms, phrases, and theories that may not be accurately or appropriately understood in other settings or other relationships.

While the first two types of discourses are tempered by other areas of expertise, and must take into account how these fields think and process (such as with contractors or engineers), or may be watered down with generic terminology for clients, conversations within education are relatively unburdened by these types of limitations. From this perspective, the educator/ peer or educator/student conversations should be the most robust, and a starting point for how other discourses will occur once they are modified for other expertise areas.

Another lens through which to explore environmental discourse is architecture's position bridging Art and Science. Each of these distinct fields, of course, has considerably different methods of communication. In all situations, it is important to learn to communicate in the language of a specific field in order to become a member of that community. ${ }^{4}$ Scientists understand how best to communicate with scientists, engineers understand how best to communicate with engineers, and designers understand how best to communicate with designers. Different architecture programs land in different locations along the Art-Science spectrum, and their internal discourses reflect that position. Some programs lean toward a building science perspective while others more heavily emphasize formal (or Big "D") design, while still others lean toward ecological or historical influences. Each of these focus areas comes with a slightly different emphasis. It then follows that there are slightly different written and verbal communication methods for each, even within these similar strands, that facilitate active participation within the various subcommunities and circles of architectural education.

\section{Environment}

Given these frequent and distinctive discourse types within design, an obvious challenge comes with overlaying a complex subject such as the environment. Just as design issues are discussed in various ways, environmental themes also bring their own complexity to communication. As Basa reiterates, building on Teymur, in the 1960s and 1970s the concept of the environment in architecture morphed into a shorthand term for nature, and began to encompass everything from cities, space, buildings, wildlife, energy, forests to any number of other concepts. ${ }^{5}$ Overlaying these two fields effectively layers complexity upon complexity.

This exploration, then, attempts to pull apart some of that complication by proposing categories for environmental discourses in architectural education, and looking at rhetoric used within those discourses. Specifically, what types of discourses do the participating educators experience related to environmental issues, and what methods do they use to try to communicate their goals within those conversations? How are environmental discourses in design education being approached, what strategies are favored, and why?

Arguably more important than issues of graphic presentation is the question of how environmental discussions are brought into design coursework to allow for a robust conversation around complex sustainability concerns. As Dryzek notes, "language matters ... the way we construct, interpret, discuss, and analyze environmental problems has all kinds of consequences." ${ }^{16}$ Being the space to house comprehensive, unfettered conversations, the academic discourse should be strategic and thoughtful. How these themes are discussed by and around developing designers is critical. These discourses are the focus of this exploration.

\section{Research Questions}

The primary question for this research exploration is: How is environmental discourse perceived in courses and program structure within architectural education? This line of questioning addresses the larger issues of discourse and rhetoric in architectural education, and how environmental themes are approached.

A secondary research question addresses what types of environmental terms are used within education. How are themes addressed within the larger curriculum? Ensuring that students have the critical ability to assess strategies and speak fluently about these issues is imperative. This question also seeks to understand how faculty members navigate environmental terms and rhetoric within the classroom to work toward a sustainable goal. 


\section{METHODOLOGY}

This study uses an interpretivist qualitative research approach, emphasizing the self-reflective nature of how qualitative research is conducted. This enabled the researcher to make sense of - or interpret - the beliefs that different participants hold about incorporating sustainability in their courses. ${ }^{7}$ While the term interpretivism is occasionally used interchangeably for all qualitative inquiry, this study is specific in its application of the term as that "the meaning of human action is inherent in an action, and that the task of the inquirer is to unearth that meaning." 8 These interpretations allow the creation of a broad and rich description of the architectural education culture itself, focusing on patterns and connections instead of causality. ${ }^{9}$ This approach emphasizes how the participants make sense of their situations, illustrating patterns with which the entire design profession may identify. In the context of the complexities of both design and the environment, the focus is on "how these competing approaches reflect the cultures of people who are involved in this process of architectural making."10

\section{Research Strategy: Grounded Theory}

This research followed the general guidelines of grounded theory as laid out by Strauss and Corbin, ${ }^{11}$ with modifications from other qualitative researchers such as Charmaz ${ }^{12}$ and Creswell. ${ }^{13}$ The primary data was collected through in-depth interviews in narrative form. The principal validation strategy for the exploration was member checking, and the additional criteria of credibility, originality, resonance, and usefulness were also used to assess the validity of the study. ${ }^{14}$

Grounded theory methodology focuses on the generation or discovery of a theory to develop a framework for further research. ${ }^{15}$ The grounded theory approach assumes "that all of the concepts pertaining to a given phenomenon have not yet been identified, at least not in this population and place. Or, if so, the relationships between the concepts are poorly understood or conceptually undeveloped." 16

Specific to this paper, the exploration focused on how environmental themes are discussed in both courses and larger program structures. The grounded theory process helped to distill the perceptions of each participant, and establish similarities in the participant group as a whole, as shown through the interviews and narratives. Through the detailed understanding of participants' educational methods, experience patterns and preferences were revealed to provide a framework for further exploration.

\section{Participant Selection}

The participant pool for a grounded theory study, focusing specifically on the goal of generating a theory from pertinent participant insight, is determined based on the participants' potential to contribute to the development of a theory. ${ }^{17}$ As Charmaz ${ }^{18}$ notes regarding an interview with grounded theorist Jane Hood, "Theoretical sampling is purposeful sampling but it's purposeful sampling according to categories that one develops from one's analysis and these categories are not based upon quotas; they're based on theoretical concerns."

A purposeful sample was established early, and included faculty members in accredited architecture programs in the United States commonly acknowledged to be successfully incorporating environmental themes in their courses. The member lists of two well-known organizations focusing on this type of integration were cross-referenced to establish the preliminary pool. Initial intensity sampling allowed for the selection of specific participants certain to contribute to the theory development, who are participating in "information-rich" cases. ${ }^{19}$

Eighteen faculty members from different schools around North America made up the initial list of potential study participants. Suggestions for additional participants were requested as interviews were held. Forty-nine potential subjects were identified; twelve were interviewed. Grounded theory studies tend to use between twelve and fifteen subjects in research; less than twelve may be too few and more than fifteen may become unmanageable. ${ }^{20}$ This small sample size was deemed effective and sufficient based on achieving theoretical saturation with the gathered information.

\section{Data Collection and Analysis}

In-depth, individual interviews were the primary source of data. Each interview began with an overarching question relating to the participant's perspective on sustainability within architectural education, addressing the larger scope of the research project. This initial question provided a framework for the discussion, and from there, the questions and discussions varied considerably, developing into an individual narrative filled with personal perspectives and experiences. As additional interviews were completed, the follow up questions and conversations became more focused to reflect the concepts and theories beginning to take shape. Strauss and Corbin outline three phases of coding analysis: open coding, axial coding, and selective coding. ${ }^{21}$ These were all used to analyze the data in iterative stages.

\section{DISCUSSION}

As the data was coded, six phenomena began to emerge as strongly related to the integration of environmental themes in architectural education. One of those phenomena addressed the notion of framework development, which participants believe begin to help the students develop tools for understanding and confronting the complexity of environmental issues. Within this topic of framework development, many participants noted that there are a plethora of terms and methods for addressing sustainability that are being used in both academia and the profession, and few - if any - of these terms have concrete definitions.

\section{Discourses}

Environmental themes are undoubtedly discussed in courses and conversations within architecture programs, but how? Participants in this study believe that there are a number of 
regular, frequent conversations that can impact the successful architecture programs in integrating sustainability themes. This breaks down the discourses in the educational space to more distinct levels: between educator and student; between peer faculty members; between faculty members and program administration; and with higher university administration. The primary concerns for participants are conversations between their faculty members, as well as formally within departments and college administrations. Participants see other important levels of conversations to be with students, practitioners, the larger university structure, and peers at other institutions, though they believe these tiers to be less influential in the success of the integration in their particular programs.

Participants firmly believe that conversations between their peer faculty members are the most important discussions to achieving success in the integration of environmental themes. Many study participants find that they have overwhelming support for including environmental themes within courses, while a few encounter superficial endorsements for the proposed integration. For those participants that experience support, faculty conversations often veer into more detailed discussions of how the program can embrace these themes within different levels, as well as how they can be incorporated within different course subjects. These conversations act as a booster for the efficacy of integration into that program.

Those participants that relate experiencing insubstantial or no support are aggravated, and feel that environmental issues do not rank equal to the importance of other faculty conversations, such as around design theory. Some participants liken the superficial support that they do get to greenwashing, another form of insincere rhetoric as reviewed earlier. One participant states:

One faculty member throws the [green] label on the studio because he feels he wants to do something. He still doesn't have all the information that he probably needs to be a really substantial designer engaging these issues, though he is a talented designer otherwise.

The participants believe that this superficial support is more harmful than no support at all, leading people to believe that effort is being given and actions are "taken care of" when they are not.

Depending on the individual situations, participants expressed feeling lucky to be in a program that accepts environmental issues as important and moves forward with purpose and solid support, or are discouraged that there is little acknowledgment or support for environmental topics. Participants in the latter position, without support, expressed attempts to incorporate these themes individually within their courses, hoping to engage students and foster their interests, regardless of how the other faculty or administration view environmental issues.
Participants have similar feelings regarding dialogues with their program administration. While most participants believe that their program leadership understands the currency of environmental issues in both education and the profession, some participants are disappointed and often feel misled based on the lack of follow through and accountability shown by their administrators. Participants in programs where they believe environmental themes are truly integrated indicated that their leaders are valid, legitimate supporters of the environmental movement. Participants not in these integrated programs feel that the support pledged by their leadership is shallow, and that peer faculty members are rarely held accountable for any integration of environmental themes. As a result, no larger, successful movements regarding environmental themes are evidenced in these programs.

Participants often feel that conversations with peers at other institutions serve as support groups; participants spoke freely about their interest in environmental issues with others in peer programs with similar positions and goals. These support conversations usually review progress that is or is not being made at each of the participants' home institutions; concerns about different programs; ideas about distinctive projects or methods to use in their courses; or opportunities for their students to get an unusual perspective on environmental themes. These conversations also address the assessment of and consistency among methods and targets for environmental themes; curricular and support needs; and initiatives that could be established to meet those needs. While the majority of the study participants view these peer groups and conversations as supportive, other participants feel they are "preaching to the choir," spending precious time chatting about environmental issues with people already invested, and not using their time effectively to get the most return on their investment. These participants say that they would rather spend their time reaching out to other populations, such as faculty experimenting with environmental issues that have not fully come into the sustainability fold.

Study participants believe that students are unquestionably interested in sustainability and green building methods. A large portion of the participants' conversations with their students address resource consumption, understanding new concepts or technologies related to sustainability, or how the students can become more deeply involved with green building projects. Students are often seen as proactive in pushing the issue, and require a response in some form from the faculty. This would include a response to the specific questions, as well as addressing issues of continuing education for faculty to ensure responses are accurate and reliable.

When study participants talk with practitioners about sustainability and green building, they nearly always meet with exceptional interest. All participants feel that many in practice understand the need to include green building strategies in their projects. These same practitioners have felt that students as a whole are not being adequately equipped to address these 
evolving and urgent concerns in the profession, though they are starting to feel a slow shift toward graduates being better prepared for these issues as found in practice. Participants both feel optimistic about this and also use it as a talking point with their faculty and administration to encourage change.

Participants mainly view discourse at the university level as developmental and experimental. While some universities are more involved with the development of sustainability initiatives than others, the study participants feel that these discussions affect a higher level beyond their direct involvement with and impact on students. Many participants are involved directly with the development, progress, and oversight of university initiatives, and while being involved is viewed as beneficial, the participants often do not see interest translating from the university level into their specific program. Similarly, while participants are officially representing their department on these universitywide committees, there is otherwise not much support of larger campus sustainability initiatives in their architecture programs.

Some participants feel that the most promising way to incite change in peer faculty members not currently on board with sustainability is to provide foundational knowledge for implementation and integration. Faculty workshops were suggested as one successful method for shifting conversations. One participant noted:

We did it with software. Our first year design instructors offered workshops during the break for faculty and they got very good attendance. Even if people aren't going to use it at least they can get a sense of what it can do. If you have faculty learn together, separate from the students. ... It went really well. Most of these people actually want to know this stuff. A lot of them do seem interested in training, but they don't want to be exposed.

Others disagree. "I offered to give a free workshop to my colleagues, and they didn't show up. The department head showed up. Nobody else. And I said to the department head, 'Why don't you force them?' He wouldn't even consider that." These experiences illustrate the frustration felt by faculty participants willing to assist other educators to sharpen their skills and bring them into a meaningful conversation, and highlight the different dynamics in each faculty body.

\section{RHETORIC AND TERMINOLOGY}

In terms of rhetoric, architecture is a field rooted in subjectivity. ${ }^{22}$ The complex, unfamiliar topics of sustainability contribute to the lack of specificity in the discourse. As Basa points out, "In the case of the environment, vagueness is not a linguistic shortcoming but the neutral representation of the vague state of the concept of the environment itself within the architectural field." ${ }^{23}$ Participants do not frequently use terms such as sustainability, green architecture, carbon neutral, and regenerative design, among others. Instead, participants focus the principles of these themes in their instruction and explanations - not the terms themselves, which they feel adds ambiguity to an already vague topic.

Participants feel that they must understand a variety of terms, but are hesitant to use them. They all believe that the importance is in defining each term in context at the time of discussion, and making certain each use is explicit between those involved in the conversation. In other words, terms may or may not have the same meaning in back-to-back conversations. The collective concern among participants is that there is just enough awareness and familiarity to use an abundance of environmental or green building terms, and students have no frames of reference regarding scales, scopes, or boundaries for this variable terminology. This supports previous literature positing that environmental discourses in architecture embolden the use of clichés, which attempt to communicate "supposedly true and known relations." ${ }^{24}$ These terms might include sustainable, ecological, and efficient. As such, participants emphasized their inclination to use qualifiers and measurable criteria instead of blanket terms with students to ensure that students understand the fundamental intent of the conversation, and what the faculty specifically mean when using particular words.

Study participants are non-committal when addressing specific terminology used in sustainability or green building conversations. Many share an apprehension about using common and easily identifiable terms such as sustainability, green building, or regenerative. One participant said, "You don't achieve sustainability by defining it," summarizing this perception. They feel that these terms are highly contextual and hold different meanings for different people with different backgrounds; there are no consistent definitions or assessments of these terms. Participants viewed this as a common, problematic issue. Another participant stated:

Until we're serious about operationalizing what the hell it is we're talking about, we just talk. The conversations are still interesting because everybody has their own origins of what they think sustainability means, or what they think design means. They're very interesting. They're very generative and fruitful.

Another participant, however, is happy to use whatever terminology comes up:

I love them all. It makes it interesting to talk about it because each one puts a little bit different filter on what you're trying to do, and I think all the terms are descriptive of good paths. Architecture is such that there's no right answer. I love the ambiguity of that.

While some participants favor using all terms at some point or another, others explicitly try to use none of these terms and prefer to speak about strategies and end goals, using terms 
like energy efficient or high performing. One participant says, "I don't teach about it, I teach the principles of it." The point of this statement being that the larger movement is not defined by one term that is more appropriate than another. This proposes emphasizing principles and strategies over the delineation of terms as a successful strategy with students.

Regardless of terms being used or not used, participants all expressed the need to actively listen during conversations to better comprehend the types of design and strategies being talked about, without relying on often misused popular terms. This active listening allows the study participants to understand all perceptions in the exchange and mentally align and filter them. This, in turn, allows the participant to respond appropriately and accurately without relying on standardized, over-used, or misunderstood terms. The study participants feel that this active listening component increases their ability to better understand student interests and opportunities for increased engagement, and also provide their students with a better foundational framework.

To help address this ambiguity in rhetoric and terms, participants often try to help their students establish a framework for their personal use and future reference. One participant shared their understanding of how the educator and designer might begin to manage these layers of complexity to incorporate sustainability issues:

You are involved in a management process of getting control over complexity. You have to be very thorough in laying out the framework issues that you're going to engage, and you have to be very articulate in presenting how you're thinking about those issues as you develop your strategies and your transformations, so it's a different approach.

Participants shared different methods in which they have success in helping students to view and organize complex problems. One participant talked about the importance of integrated design and project-based learning, and how that allows the student to develop an individual organizing process, complete with a distinct understanding of terms:

You begin to get into a design method and a planning method that capitalizes on trends, but also crystallizes it. As you begin to get that established methodology into how you're thinking, you begin to take that methodology and you begin to use it in how you plan. So effectually you're planning whole ecosystems. And that knowledge changes the whole playing field.

While this process is often very detailed, the principles that are developed guide the processes of the students and, in this progression, help them to better understand terms.
Because there are increasing regulations, incentives, and policies being enacted at the local, state, and federal levels that can have a direct impact on the design and performance of buildings, these issues are increasingly seen in the architectural dialogue. However, the issue of legislation and policy was never noted in the participant interviews as an integral part of their educational method, showing that participants do not prioritize these issues or the associated terminology in courses. When specifically questioned, most participants agreed that legislation and policies are important issues, but are difficult to include within the educational format. Legislation and policy issues are viewed by participants as an addition to the current complexities of the field, and have not yet reached a level requiring substantial inclusion into coursework.

Study participants believe that by teaching the fundamentals of sustainable design, through whatever terms and methods they decide to use, their students are - by default - becoming equipped to address legislation requirements in both their processes and products. In other words, participants principally believe that legislation and policies are being developed to prod the design and construction professions toward a higher level of environmental consciousness; by providing their students with a solid foundation in the theory and application of environmental issues, specifically addressing legislation can be overlooked at the education level. It is agreed by participants, however, that their students ought to be aware of legislation, laws, and policies, just as graduates need to be informed of building codes and the associated impacts. While these legislative criteria are sometimes reviewed in courses and curricula, particularly in professional practice courses, they are not a primary focus of the participants.

\section{CONCLUSION AND IMPLICATIONS}

This exploration aims to provide a framework from which to strategically approach environmental discourse and rhetoric in architectural education. The different types of discourse identified may be prioritized in the context of different programs, and different faculty and administration cultures. The insights gained from this study offer perceptions of challenges and opportunities surrounding these discussions in different settings.

Methods of support are suggested for architectural educators and administrators interested in better incorporating environmental themes into their programs. Cultural and organizational issues within departments can be considered by starting with the different types and goals of environmental discourse and rhetoric. Depending on individual situations and dynamics within the faculty, administration, and university, individuals can use this base information to facilitate a faculty conversation on the integration of environmental issues. If necessary, a mediator could be invited to address barriers, concerns, terminology, and opportunities specific to the program. Researchers interested in incorporating environmental themes more strategically into design education can use this work as a springboard to further unravel the complexities of rhetoric and discourse in architectural 
education.

Further research may include: understanding negative cases and opposing viewpoints within architectural education; investigating the myriad terms in the field, connotations, and popular uses, including how they are shaped and perceived; and communication patterns within architectural education and the profession, and how they differ depending on various participants. This investigation supports the belief that including environmental themes in architectural curriculum is complex and wide-ranging, and requires an exploration of not only large thematic ideas but also equally important "smaller" elements, such as individual conversation strategies.

\section{ENDNOTES}

1. Guy and Moore, 2007.

2. Basa, 2009.

3. Ibid.

4. Lemke, 1990.

5. Basa, 2009; Teymur, 1982.

6. Guy and Moore, 2007; Dryzek, 1997.

7. Creswell, 2007.

8. Schwandt, 2007.

9. Charmaz, 2006.

10. Guy and Moore, 2007.

11. Strauss and Corbin, 1998.

12. Charmaz, 2006.

13. Creswell, 2007.

14. Charmaz, 2006.

15. Strauss and Corbin, 1998; Creswell, 2007.

16. Strauss and Corbin, 1998.

17. Creswell, 2007.

18. Charmaz, 2006.

19. Patton, 2002.

20. Bowles, 2007.

21. Strauss and Corbin, 1998.

22. Aureli, 2012; Mark, 2013; Rawes, 2013.

23. Basa, 2009.

24. Basa, 2009; Chaffee, 1988.

\section{REFERENCES}

Aureli, Pier Vittorio. "Redefining the Autonomy of Architecture: The Architectural Project and the Production of Subjectivity." Harvard Design Magazine 35 (2012): 106, 111, 188. ProQuest. Web. November 17, 2014.

Basa,Inci. "EnvironmentalDiscourse of Architecture." International Journal of Environmental Studies 66.2 (2009): 259-267. Print.

Berger, Peter L., and Thomas Luckmann. The Social Construction of Reality; A Treatise in the Sociology of Knowledge. Garden City, N.Y.: Doubleday, 1966. Print.
Bowles, T. A. (2007, October). Grounded Theory. Introduction to Qualitative Research in Adult \& Higher Education. Lecture given at North Carolina State University, Raleigh, N.C.

Chaffee, John. Thinking Critically. Boston, Mass.: Houghton Mifflin Co, 1988. Print.

Charmaz, Kathy. Constructing Grounded Theory: A Practical Guide Through Qualitative Analysis. London: Sage Publications, 2006. Print.

Creswell, John W. Qualitative Inquiry and Research Design: Choosing Among Five Approaches. Thousand Oaks, Calif.: Sage Publications, 2007. Print.

Dryzek, John S. The Politics of the Earth: Environmental Discourses. Oxford, England: Oxford University Press, 1997. Print.Guy, Simon, and Steven Moore. "Sustainable Architecture and the Pluralist Imagination." Journal of Architectural Education (2007): 15-23. Print.

Lemke, J. L. Talking Science: Language, Learning, and Values. Norwood, N.J.: Ablex Publishing Corporation, 1990. Print.

Mark, Laura. "Five Views on Sustainability in Architectural Education." The Architects' Journal (2013). ProQuest. Web. November 17, 2014.

Patton, Michael Quinn. Qualitative Research and Evaluation Methods. Thousand Oaks, Calif.: Sage Publications, 2002. Print.

Rawes, Peg. Relational Architectural Ecologies: Architecture, Nature and Subjectivity. New York: Routledge, 2013. Digital.

Schwandt, Thomas A. The SAGE Dictionary of Qualitative Inquiry. Los Angeles, Calif: SAGE, 2007. Print.

Strauss, Anselm L., and Juliet M. Corbin. Basics of Qualitative Research: Techniques and Procedures for Developing Grounded Theory. Thousand Oaks, Calif.: Sage Publications, 1998. Print.

Teymur, Necdet. Environmental Discourse: A Critical Analysis of Environmentalism in Architecture, Planning, Design, Ecology, Social Sciences and the Media. London, England: Question Press, 1982. Print. 